\title{
Teach Me In The Way I Learn: Education And The Internet Generation
}

Russell Baker, (E-mail: rbaker1@ju.edu), Jacksonville University Erika Matulich, (E-mail:ematulich@ut.edu), University of Tampa Raymond Papp, (E-mail: rpapp@ut.edu), University of Tampa

\begin{abstract}
College students learn differently than their professors. This disconnect between learning styles is not a new problem, however the problem has been magnified by the technology driven environment which exists in contemporary higher education. Students who grew up using computers and Playstations while surfing MySpace blogs and listening to their MP3 players are frequently neither receptive to traditional lectures nor able to relate to examples based on $20^{\text {th }}$ century technologies. Numerous tools and technologies, however, can be used effectively to teach college students. This paper discusses several methods of addressing this disconnect through both pedagogical technique and classroom technologies.
\end{abstract}

\section{LEARNING PREFERENCES}

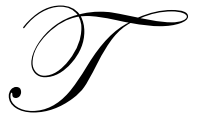

raditional college-aged students, those born in the 1980's and early 1990's, are referred to as Millennials, the Net Generation (Oblinger, 2005), or simply as Generation Me (Twenge, 2006). Regardless of their moniker, they share distinct learning styles and behaviors. They prefer to learn at their own pace. They like and are comfortable with an on-line environment for testing, lectures, and assignments. They are informal learners, preferring "any time, any place" learning to a traditional classroom. Class time is most effective for these students when it involves interaction, demonstration and social networking. Finally, they are visual and kinesthetic learners who prefer to experience the world through multimedia and not print (Oblinger, 2003 and 2006; Twenge, 2006).

This learning style often presents problems for faculty since most are part of the "baby boomer" generation and learn much differently than their students. Faculty prefer to learn by reading and listening to a lecture. Students are visual learners who prefer multimedia and experiential learning. It is this dramatic difference in learning preference that creates a disconnect between students and professors. Figure 1 highlights the generational differences and preferences (Oblinger, 2005).

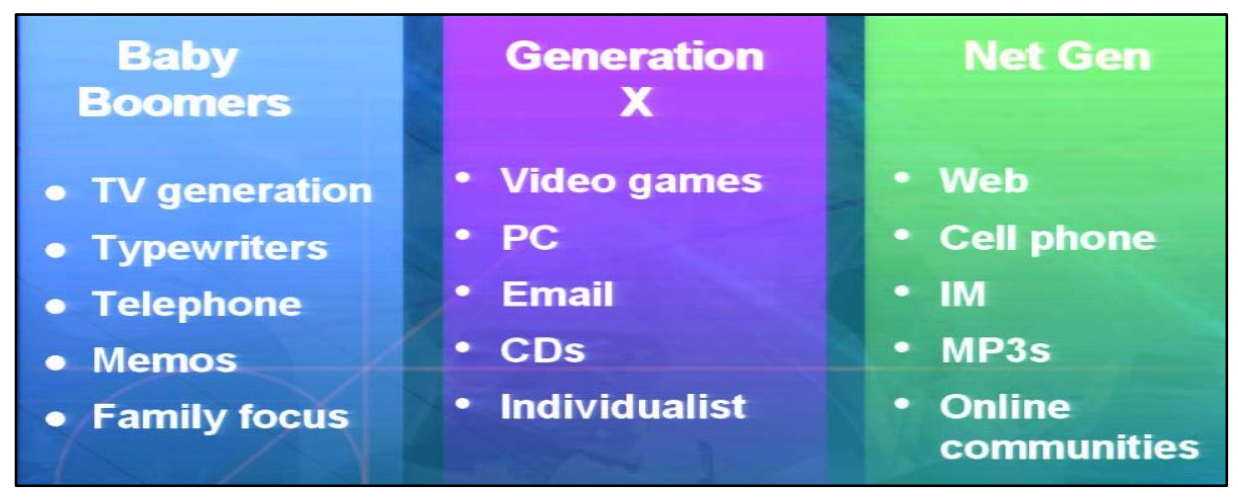

Figure 1: Comparison of Learning by Generations (Oblinger, 2005) 
To fully appreciate the differences, one only needs to analyze the life of a 21 year old. Today's average 21year old has spent 10,000 hours playing videogames, 20,000 hours watching TV, 10,000 hours talking on their cell phone, sent 250,000 emails and only 5,000 hours reading (Oblinger, 2005). As a result of this exposure to a multimedia environment, their brains have developed to respond to such stimulation and they process information differently than their professors, parents, and just about anyone older then them. Yet when they reach college, they are often asked to read copious amounts of material from textbooks, which they find boring and are unable to successfully process. This directly impacts their view of the professor, the topic, and even the college environment itself. The subsequent discussion explores the differences in information processing between the generations.

\section{INFORMATION PROCESSING}

Today's student processes information visually and learns much differently from their "baby boomer" or "Generation Y" professors. Their brains are "wired" differently than that of their professors, hence their development and experiences guide how they process information and experience the world. While most faculty process information in a sequential or liner fashion, students process information in a randomized or networked pattern which allows them to build concept maps (see figure 2). This seemingly random information processing alludes to the need for a variety of learning opportunities and methods. Student learners do not gain much of their knowledge in the classroom, but rather outside it after they have had a chance to reflect on the information. The average student's attention span is only seven minutes (Oblinger, 2006). Consequently, if students are asked to sit through a traditional 50-minute class that involves lecture only, they will become disinterested and disengaged very quickly. Therefore, it is important to use several pedagogical methods and vary the pace of learning.

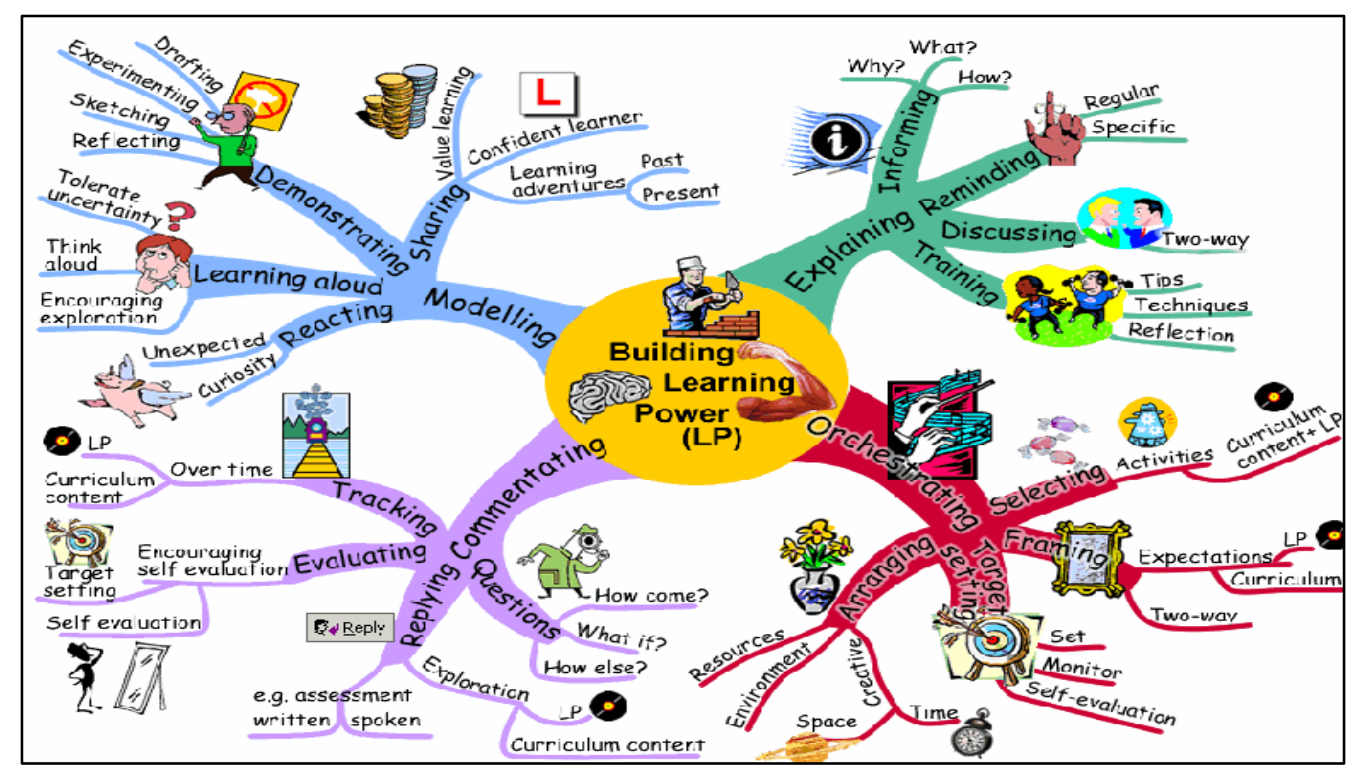

Figure 2: OpenMind ${ }^{\mathrm{TM}}$ Concept Map (Oblinger, 2006)

Breaking concepts into 10-minute "chunks" will help students retain material, but only if they have time to process the information interactively and have a chance to reflect on it. They prefer self-paced learning, engagement from and with their peers, real experiences and find relevance in "things that matter" to them. In fact, they might even ask you to clarify “what's in it for me?” (Oblinger, 2006) 


\section{AN LMS TO MAKE IT RELEVANT}

As faculty, we need to ask ourselves serious, reflective questions regarding how this is to be accomplished. How can we make our classes more relevant and applicable? One way is to accept and even embrace the on-line learning environment. Learning management systems (LMS) such as Blackboard ${ }^{\mathrm{TM}}$, WebCT ${ }^{\mathrm{TM}}$, Sakai ${ }^{\mathrm{TM}}$ and Moodle ${ }^{\mathrm{TM}}$ make it easy to communicate with students and they prefer the "any time, any place" accessibility of information. Most students do not even learn and/or study during the day, save for attending their classes. Most of their work is done between the hours of 9 p.m. and 3 a.m. (based on accumulated data from the University of Tampa Blackboard site). Check your university's LMS student access statistics if you're not convinced!

Today's student prefers on-line environments for everything from assignments to homework to testing, and faculty need to incorporate such learning into their courses. Class time can be used for interactivity, demonstration, and peer learning. Students also prefer group activities and collaborative projects. They like to brainstorm and spend considerable time in on-line discussion boards and Blogs (web logs or journals). In fact, some of the most popular learning environments today involve the use of Wikis (on-line editable web encyclopedias) and Blogs (Alexander, 2004; Chen, 2005; Higdon, 2005). This is a culture that is very social and thrives in on-line communities. Just ask your students!

To engage these students, a course must incorporate multimedia as well as kinesthetic experiences. Students like simulations and role playing scenarios as they prefer to experience things from a realistic, practical standpoint. That's part of the reason that they won't listen to a lecture-they need to go out and experience it for themselves sometimes despite the consequences. To cater to this learning style and preference, real-world projects and tasks are excellent ways for them to experience the real word and focus on the WIIFM (What's In It For Me) mindset. Figure 3 illustrates the continuum of learning. A successful learning experience will balance both ends of the continuum (Oblinger, 2005).

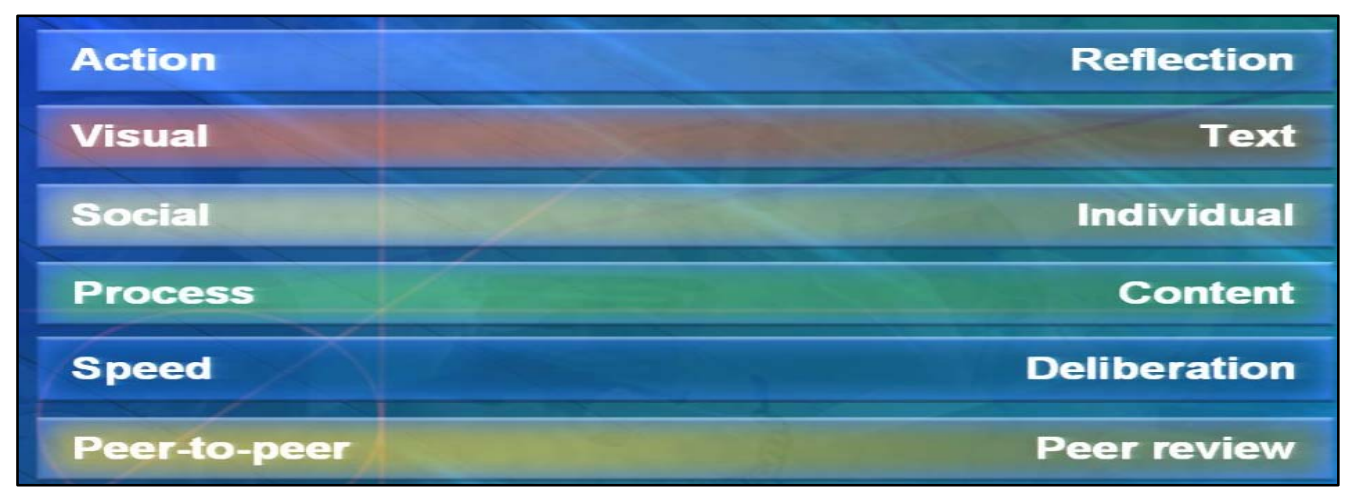

Figure 3: Range of Learning (Oblinger, 2005)

\section{TOOLS AND TECHNOLOGIES}

There are many tools and technologies available to the instructor which can be used to create interesting, relevant learning opportunities. One of the easiest and most common is to use PowerPoint to incorporate some multimedia into a lecture. It is imperative that professors not read from the slides directly as the students perceive this in a negative way. Instead, use PowerPoint as a basis to begin an interactive discussion in which students can share their views and experiences with each other. It's also important not to rely exclusively on PowerPoint as means of content delivery. Students refer to this as "Death by PowerPoint" and it is only marginally better than a straight lecture. On-line discussions, particularly those done asynchronously, are an excellent way to engage students as discussions can begin before the class session does and/or continue long after the class is over. Remember, students 
learn by building concept maps and they may not "get it" in the classroom, but rather later on after they have had a chance to reflect on what was presented (Chen, 2005; EduCause 2005 Annual Conference, 2005).

Interactivity, albeit necessary, can be challenging to implement. How can an entire class be interactive? The solution involves engaging the students-often. Recall that most students have a 7-minute attention span. Technologies like Turning Point's Audience Response System ${ }^{\mathrm{TM}}$ (AKA “clickers") can be used to assess their comprehension, interest and opinion. If students believe that faculty care, they are more likely to be engaged and learn. Students also like playing with "digital toys" like the clickers. Varying the method of presentation is also important. Intertwined in the lecture should be video and/or audio clips that students can listen to either in class or afterward-remember they learn visually and like multimedia. There are many web-based simulations and demonstrations available for use in the classroom. Web-based tools like Google Earth ${ }^{\mathrm{TM}}$ allow the student to interact with technologies keeping them interested while they learn (Matulich \& Papp, 2006; Papp, 2006).

There are also many software tools that are available for creating multimedia lectures and presentations (see Figure 4). For example, MatchWare's Mediator ${ }^{\mathrm{TM}}$ allows website design without any knowledge of HTML or programming. Students take to this very quickly and are often able to create applications without any formal training - they just click and learn on their own by doing. Most software packages like this feature rich, easy to use and reasonably priced. Another MatchWare product, ScreenCorder ${ }^{\mathrm{TM}}$, is excellent for recording voice-overs on your PowerPoint slides. Students like the ability to listen to the lecture when it is most convenient for them and when they need to process the material again. This works well in both on-line and traditional classroom learning environments as students have access to the material and can listen to it at their convenience. Finally, MatchWare's OpenMind ${ }^{\mathrm{TM}}$ allows concept maps to be built either from scratch by students for their own use or by instructors for their students. In fact, a traditional outline format can be created and then converted to a concept map (see Figure 2). The product is excellent for websites, presentations and general note taking by students. It is also very easy to use and contemporary technology-aware students frequently do not need any training on how to use it (MatchWare, 2006). Recall that students are visual and kinesthetic learners and you may experience their "show me how and get out of my way" mindset.

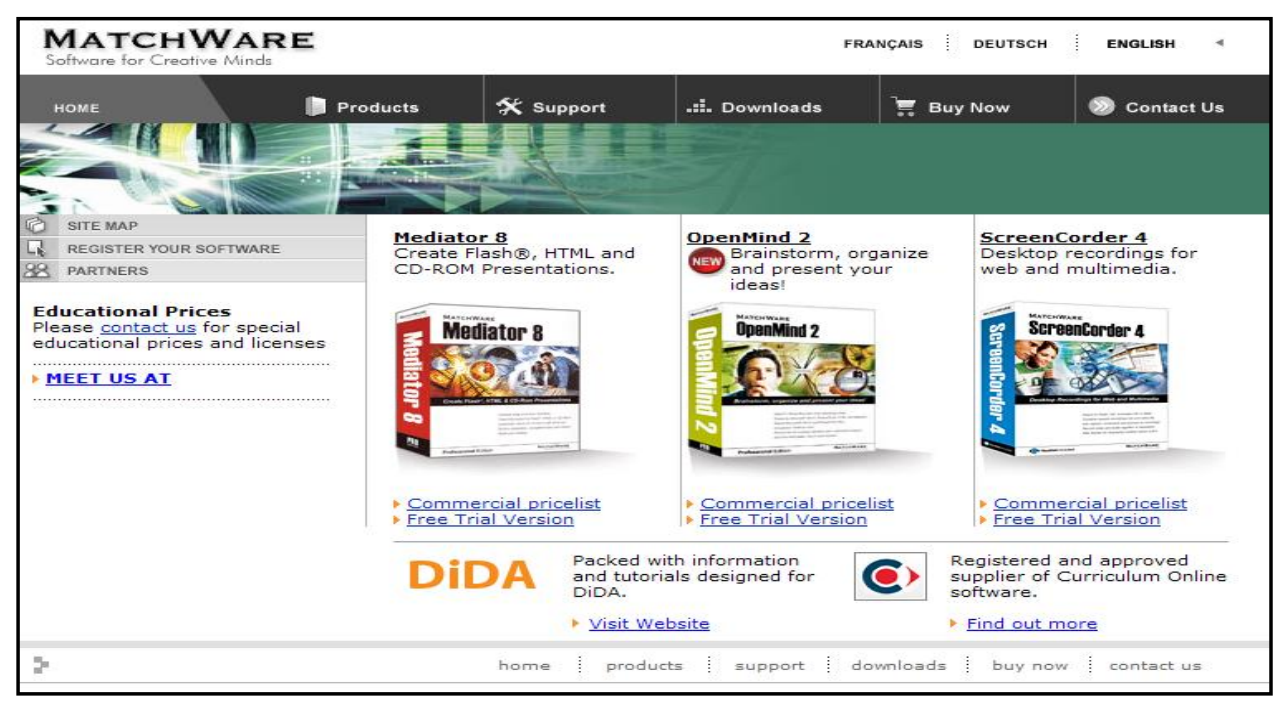

Figure 4: MatchWare's ${ }^{\mathrm{TM}}$ Software Suite (www.MatchWare.com) 


\section{LEARNER EXPECTATIONS}

Technology aside, students must be engaged using the thee H's: Head, Heart and Hands. Most students do not question the instructor's knowledge on the subject-to the contrary-they expect the instructor to be an expert in the topic and be able to pass that knowledge on to them. Students also need to feel that the instructor has a heart and cares for the students. This includes responsiveness and empathy for them and their problems. It also includes an enthusiasm for the topic and teaching in general. Luckily, for most teachers this is not too difficult! Finally, good teaching skills are necessary. Use of the "hands" to convey ideas at the right level, in a clear and systematic manner which stimulates their interest and learning is vital (Oblinger, 2005; Twenge, 2006). The physical environment in which students learn is also important. As previously mentioned, today's students are "any time, any place" learners who prefer informal learning spaces to more formalized ones. To this extent, they embrace and even demand a wireless environment where they can connect to the Internet and share information in the form of email, instant messaging, blogs and the ability to just search for information on the web. Flexible classrooms that have moveable chairs and even walls help to diminish the visual barriers and enable group interaction are desirable and cost effective (Long, 2004; Skipton, Matulich, Papp, \& Stepro, 2006).

\section{PUTTING IT ALL TOGETHER}

We live in a dynamic, global and increasingly "flat" world where technology is all around us (Friedman, 2006). Students have distinct learning styles and as instructors, we need to adapt. Today's student is more technology savvy than ever before and their comfort with the digital environment presents a challenge for some professors who may be less than comfortable with this new paradigm. If you have not already done so-and if you have not been convinced by this paper-you need to begin to look at your course delivery methods and incorporate some of the new technologies discussed. There are several learning outcomes that remain over time such as communication skills, critical thinking, problem solving and collaboration. Key concepts and ideas notwithstanding, the methods with which they are communicated to students are paramount. College is the place to allow students learn and explore new ideas and topics as they prepare for a future that has never been more uncertain, but also one that has never had as many possibilities. Generation Me will soon enter the workforce and become the future leaders. We need to do all we can to prepare them for a dynamic, uncertain and clearly digital world.

\section{NOTE}

Authors are listed in alphabetical order. All authors are equal contributors.

\section{REFERENCES}

1. Alexander, B. (2004). Going Nomadic: Mobile Learning in Higher Education, EDUCAUSE Review, vol. 39, no. 5 (September/October 2004).

2. Chen, H. (2005). Reflection in an Always-on Learning Environment: Has It Been Turned Off? Retrieved from http://www.campus-technology.com/article.asp?id=11802 on February 13, 2006.

3. EduCause 2005. Annual Conference (2005). Retrieved from http://www.educause.edu/e05 on February 13, 2006.

4. Friedman, J. (2006). The World is Flat: A Brief History of the Twenty-first Century. Farrar, Straus and Giroux.

5. Higdon, J. (2005). Teaching, Learning, and Other Uses for Wikis in Academia: All Users Are Not Necessarily Created Equal Retrieved from www.CampusTechnology.com on February 13, 2006.

6. Long, P. (2004). Learning Object Repositories, Digital Repositories, and the Reusable Life of Course Content Retrieved from www.CampusTechnology.com on February 13, 2006.

7. MatchWare (2006). Retrieved from www.MatchWare.com on February 13, 2006.

8. Matulich, E. and Papp, R. (2006). Clickers in the Classroom: Engaging the Millennial Learner Campus Technology 2006 Conference (July 31, 2006).

9. Oblinger, D. (2003). Boomers, Gen-Xers, and Millennials: Understanding the 'New Students' EDUCAUSE Review, vol. 38, no. 4 (July/August 2003). 
10. Oblinger, D. (2005). Listening to What We're Seeing OCLC Distinguished Seminar Series (August 25, 2005).

11. Oblinger, D. (2006). Educating the NetGen retrieved from www.EDUCAUSE.edu on February 13, 2006.

12. Papp, R. (2006). Clickers in the Classroom: Reaching the Millennial Learner, Proceedings of the 2006 Southern Association for Information Systems Conference, 123-27.

13. Skipton, C., Matulich, E., Papp, R., and Stepro, J. (2006) Moving from 'Dumb' to 'Smart' Classrooms: Technology Options and Implementation Issues Journal of College Teaching and Learning, 3(6), 19-27.

14. Twenge, J. (2006). Generation Me. Free Press.

\section{NOTES}

